\title{
Epidemiological Significance of Crown Rot in the Fruiting Field in Relation to Colletotrichum gloeosporioides Infection of Strawberry Nursery Plants
}

\author{
Mahfuzur Rahman and Frank J. Louws, Department of Plant Pathology, North Carolina State University, Raleigh 27695
}

\begin{abstract}
Anthracnose crown rot (ACR), caused by Colletotrichum gloeosporioides, is a serious disease of strawberry (Fragaria $\times$ ananassa) in the southeastern United States, and there is a need to determine the link between nursery and fruiting-field disease risk. A 2-year study in 2007, repeated in 2008, was conducted at the North Carolina State University Horticultural Crops Research Station, Clinton, using 'Chandler', the most popular cultivar in North Carolina and one that is highly susceptible to ACR. Mother plants in a summer nursery were inoculated midseason with three pathogenic strains of $C$. gloeosporioides at an incidence level of $0,5,10$, or $25 \%$. Asymptomatic runner plants were selected at maturity ( 85 to 88 days after inoculation) from the nursery in early to mid-October from within a $0.5-\mathrm{m}$ (inner) or 0.5 - to $1.0-\mathrm{m}$ (outer) radius around inoculated mother plants and planted into a plasticulture fruiting field system, with fruit harvest in April to June the following spring. Plants collected from the $25 \%$-inner treatment had the greatest area under the disease progress curve (AUDPC) values, with a terminal

ACR-related plant mortality of 32 and $20 \%$ by the end of fruit harvest and marketable yield losses of 30.5 and $30.2 \%$ in 2007-08 (Yr1) and 2008-09 (Yr2) seasons, respectively. All treatments increased AUDPC values compared with noninoculated treatments except the 10\%-outer $(\mathrm{O})$ and 5\%-O treatments in $\mathrm{Yr} 1$ and $\mathrm{Yr} 2$, respectively. Marketable yield decreased $291.6 \mathrm{~kg} / \mathrm{ha}$ for every percent increase in inoculum level (i.e., 0 to $25 \%, R^{2}=$ $0.696, P=0.001)$. Levels of quiescent infection $(\mathrm{QI})$ incidence (percentage of sampled leaves) assessed 25 to 28 days before digging runner plants also directly affected yield. For example, yield decreased $131.0 \mathrm{~kg} / \mathrm{ha}$ for every percent increase in QI incidence in mother plants $\left(R^{2}=0.744, P=0.001\right)$. Immersion of plants in fungicide solutions prior to planting decreased AUDPC values and improved plant stand by 7 to $11 \%$ but did not affect marketable yield compared with controls. This study provides results that can enable nursery and fruit growers to assess risk and implement mitigation measures to limit nursery plant and fruit yield losses.
\end{abstract}

Anthracnose crown rot (ACR), caused predominantly by Colletotrichum gloeosporioides (Howard and Albregts 1983) and, to a lesser extent, by C. fragariae (Brooks 1931; Horn and Carver 1963; Howard and Albregts 1984), caused significant losses (up to 70\% plant death) to strawberry nursery and fruit growers in recent years in the southeastern United States (Southeast), where warm, moist conditions and abundant rainfall favor growth and rapid dissemination of the pathogen (Mangandi et al. 2015). Although C. acutatum and C. fragariae sometimes are involved with ACR observed in this region (Howard and Albregts 1984; Legard et al. 1998), C. gloeosporioides causes most of the ACR. This pathogen could be readily isolated from crowns of wilted plants showing typical symptoms in both the nursery and the fruiting field, based on samples analyzed at the North Carolina State University (NCSU) Plant Disease and Insect Clinic (F. J. Louws, personal observation). It is possible that many if not all $C$. gloeosporioides isolates from strawberry were described as $C$. fragariae prior to the updated species definition of Gunnell and Gubler (1992). Many investigators conducted studies on genetic relatedness among different strains of C. gloeosporioides and C. fragariae (Cannon et al. 2000; Howard and Albregts 1984; Mills et al. 1992; Sreenivasaprasad et al. 1992, 1996). Recent reclassification of $C$. gloeosporioides by Weir et al. (2012) recognized this species complex as a well-supported clade and accepted 22 species and one subspecies. However, $C$. fragariae was not included.

C. gloeosporioides can kill strawberry plants by aggressively invading and producing a reddish-brown to marbled orange necrosis of crown tissue, resulting in plant collapse. Although inoculum sources for plants in fruiting fields can be diverse, nonsymptomatic infected (quiescent or latent) planting stock is one of the most important sources of inoculum (Leandro et al. 2003; Smith 2008). Quiescent infection (QI) is defined as a period during which an infection

Current address of M. Rahman: WVU Extension Service, West Virginia University, Morgantown 26506.

Corresponding author: M. Rahman; E-mail: mm.rahman@mail.wvu.edu

Accepted for publication 2 February 2017.

C) 2017 The American Phytopathological Society is present within a host and may remain asymptomatic (Prusky and Lichter 2008). QI is primarily attributed to the presence of preformed antifungal compounds in host tissues, activation of induced resistance, or a complex series of physiological and biochemical interactions between the pathogen and the host (Prusky and Lichter 2008) that restricts pathogen growth. C. gloeosporioides is considered a hemibiotrophic pathogen; therefore, colonization in strawberry leaves may appear as a QI but the pathogen may still continue to multiply. A closely related pathogen, C. acutatum, is known to sporulate on strawberry tissue without showing symptoms (Leandro et al. 2003).

ACR epidemics in the Southeast revealed the association of the problem in fruiting fields with asymptomatic plants imported from transplant supply nurseries, as either tips or bare-root plants, and documented through trace-back analysis (F. J. Louws, personal observation). However, alternative noncultivated hosts can also be the source of inoculum in the fruiting field (Rahman et al. 2015; UreñaPadilla et al. 2002; Xiao et al. 2004). The use of "disease-free transplants" is the first and most effective method for controlling ACR in fruit production fields (McInnes et al. 1992) because popular cultivars used in the Southeast region are highly susceptible to C. gloeosporioides, and cultivars with complete resistance to ACR are unknown (Delp and Milholland 1981; Smith and Black 1987). However, considerable breeding efforts are underway to release ACR-resistant strawberry cultivars (MacKenzie et al. 2006; Mangandi et al. 2015). Although ACR is observed in fruiting fields during the winter and spring production season, it is most severe in summer nurseries in the Southeast, when prolonged high temperature and relative humidity combined with frequent rains or thunderstorms favor disease progress. Symptoms may occur in the nursery but the polycyclic multiplication of the pathogen leads to widespread incidence of runner plants that may remain asymptomatic (Rahman et al. 2015). When these plants are transplanted in fruiting fields, they may fail to establish or die as the season progresses. Typically, sprinkler irrigation is used in the Southeast for up to 10 days posttransplanting to facilitate plant establishment and this may favor pathogen spread and movement of spores down into the crown, leading to widespread ACR development (MacKenzie et al. 2009).

In previous work (Rahman et al. 2015), information was developed about inoculum source and dispersal potential in strawberry 
nurseries that could guide nursery grower decisions to rogue infected plants as an important integrated pest management (IPM) tactic to limit losses or design other management tactics. However, it is not possible to guarantee that roguing removes all potentially infected plants. The challenge for both nursery and fruit growers is that there is limited data concerning the correlation of inoculum load or disease incidence in the nursery and the potential yield losses in fruiting fields. In many cases, fruiting field growers need to decide whether plants should be used or rejected, a difficult decision if available plants are in short supply. In addition, if plants are known to be infected, very limited data are available concerning mitigation measures to limit plant losses and negative yield effects in the fruiting field.

We hypothesized that inoculum dispersal and multiplication of the pathogen on nursery plants would determine disease severity and performance of transplants in the fruiting field. There is very limited information on the epidemiological significance of nursery plant infection by $C$. gloeosporioides on plant collapse and yield loss in fruiting fields. The objectives of this research were to (i) determine the relationship between levels of plant infection by $C$. gloeosporioides in the nursery and crown rot severity in fruiting fields, (ii) assess the effect of ACR severity in plant nurseries on marketable berry yield and plant biomass in fruiting fields, and (iii) evaluate the efficacy of preplant fungicide treatments (prior to transplanting in fruiting fields) in controlling ACR.

\section{Materials and Methods}

Bare-root plant collection from inoculated nursery. A strawberry nursery was established at the NCSU Horticultural Crops Research Station, Clinton, and mother plants were inoculated at different inoculum levels, as described by Rahman et al. (2015). Briefly, fresh-dug bare-root plants from the NCSU certification program ("disease-free") were field set in broadcast-fumigated soils during spring 2007 and again in 2008. The most popular cultivar in the Southeast region (outside of Florida), 'Chandler', was used, and it is highly susceptible to ACR. Each experimental unit was composed of five rows, $1.1 \mathrm{~m}$ apart. Plants were spaced $0.5 \mathrm{~m}$ apart within each of the five rows so that each plot contained 60 plants. Plants were inoculated 85 to 88 days before digging using an equal mixture of spores of three pathogenic strains of $C$. gloeosporioides. In total, $0,3,6$, or 15 of the 60 plants in a plot were inoculated to represent the four "nursery field" treatments with a $0,5,10$, and $25 \%$ inoculation level. Plants were selected for inoculation using a restricted randomization protocol so that 3 to 6 plants were inoculated across the five rows or each of the five rows had multiple inoculated plants $(n=15)$. These four treatments were arranged in a randomized complete block design (RCBD) with four replications, separated by a $1.5-\mathrm{m}$ aisle; interplot interference was satisfactorily restricted and lack of contamination due to external sources of inoculum was validated (Rahman et al. 2015). Flags were placed next to each inoculated mother plant at the time of inoculation to facilitate identification of the mother plant at the end of the season, by which time runner (daughter) plants covered the whole plot. Two circles measuring 0.5 and $1.0 \mathrm{~m}$ in radius around each inoculated mother plant were drawn with spray paint prior to runner plant collection for this study. Runner plants were harvested at maturity in the second to third week of October, with foliage 15 to $22 \mathrm{~cm}$ tall and well-formed fibrous root systems. Runner plants with entire bare roots from each of the $0,5,10$, and $25 \%$ mother plant-inoculation treatments were dug from inside (I: $0.5 \mathrm{~m})$ and outside $(\mathrm{O}: 0.5$ to $1.0 \mathrm{~m})$ the $0.5-\mathrm{m}$ radius circle and kept separate. Thus, each inoculum level, except the noninoculated treatment, resulted in two distinct treatments, destined for the fruiting field (e.g., 5\%-I and 5\%-O, 10\%-I and 10\%-O, and 25\%-I and 25\%-O; Fig. 1). Bare-root runner plants from noninoculated nursery plots ( $0 \%$ treatment) were collected without separating them based on distance from the mother plants. All bare-root plants were transplanted in the fruiting field immediately after digging from the nursery.

Two additional sets of plants were prepared for inclusion in the fruiting field experiments. Bare-root plants from the $10 \%$ mother plant inoculation treatment inside the $0.5-\mathrm{m}$ circle $(10 \%-\mathrm{I})$ were collected to evaluate the utility of different fungicide treatments just prior to transplanting in the fruiting field and detailed below. Another set of plants consisted of nonrooted runner plants (tips) collected from inside the $0.5-\mathrm{m}$ radius of the $25 \%$ nursery treatment 1 month prior to collection of bare-root plants, and these were grown as plug plants (25\%-Plugs) in a greenhouse (Durner et al. 2002). Plug production refers to the grow-out of strawberry transplants in multicell propagation trays, starting with nonrooted tips cut from mother plant runners in the nursery field; plants grow a mass of roots (plugs) after 4 to 5 weeks and can be field set in fruiting fields. Thus, the total number of treatments in the fruiting field for these experiments was $10(0 \%, 5 \%-\mathrm{I}$ and $5 \%-\mathrm{O}$, $10 \%-\mathrm{I}$ and $10 \%-\mathrm{O}, 25 \%-\mathrm{I}$ and $25 \%-\mathrm{O}, 10 \%-\mathrm{I} \times$ two fungicide treatments, and 25\%-Plugs; Fig. 1). In all cases, only healthy-appearing and asymptomatic bare-root plants and plug plants were used in the fruiting field grow-out experiments.

Incidence and severity of inoculum levels over time were documented using a paraquat assay (Cerkauskas and Sinclair 1980) to assess the presence of QI in asymptomatic leaves to verify colonization success soon after inoculating (verifying $100 \%$ success; data not shown) and again 25 to 28 days prior to collection of the bare-root plants from the nursery. Briefly, this assay uses healthy and whole green leaves surface sterilized, rinsed, dipped in paraquat, rinsed $2 \times$ in sterile distilled water, incubated for 7 days, and scored for $C$. gloeosporioides growth on the senescent leaves. Incidence was determined as the percentage of

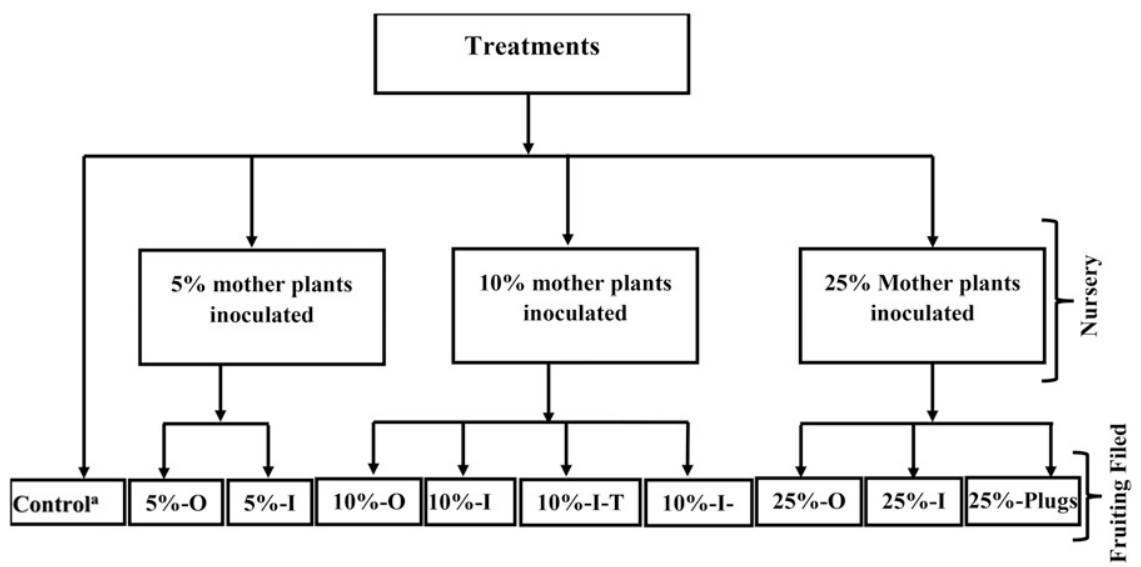

Fig. 1. Fruiting field treatments as affected by plant source from the nursery. In total, $0,5,10$, and $25 \%$ of the mother plants were inoculated in the nursery with Colletotrichum gloeosporioides conidia, and bare-root transplants for the fruiting field experiment were selected from within $0.5 \mathrm{~m}$ of the mother plant (inner [l]) or beyond this radius (outer [O]: 0.5 to $1.0 \mathrm{~m})$. Plants were also selected from $10 \%-\mathrm{I}$ to treat with fungicides Topsin-M $(10 \% \mathrm{l}-\mathrm{T})$ and Switch $(10 \% \mathrm{l}-\mathrm{S})$ and tips were selected for plug production from the nursery $25 \%-\mathrm{I}$ inoculation level (25\% plugs). Bare-root plants from $0 \%$ mother plant inoculation in the nursery were collected without separating based on distance and transplanted to fruiting fields. 
sampled leaves with Colletotrichum acervuli on the adaxial side of a leaf visible at $\times 5$ magnification after 7 days of incubation. Selected colonies were verified by observing spore morphology at $\times 200$ to $\times 400$ using a compound microscope. Severity of QI was measured as the area covered by acervular growth through visual assessment complemented with the use of a sample grid and expressed as percentage of total leaf area (Rahman et al. 2015). The same experiment was conducted in both years.

Fungicide selection and treatment of bare-root plants. Several premixed fungicide formulations or active ingredients (a.i.) effective against $C$. acutatum were tested in vitro to evaluate their efficacy against $C$. gloeosporioides (data not shown). Based on the in vitro efficacy, availability of products, and label directions, two fungicides were used to treat plants both years of the experiments: thiophanatemethyl (Topsin-M 70WP, product at $1.2 \mathrm{~g} /$ /iter of water; United Phosphorous Inc., King of Prussia, PA) (treatment code $=10 \%-\mathrm{I}-\mathrm{T}$ ) and a premix of a systemic a.i. cyprodinil and nonsystemic a.i. fludioxonil (Switch 62.5WG, product at $1 \mathrm{~g} /$ liter of water; Syngenta Crop Protection, Inc., Greensboro, NC) (treatment code $=10 \%-\mathrm{I}-\mathrm{S}$ ). The required amount of each fungicide product was mixed in 15 liters of water in a bucket by stirring with a wooden spatula and groups of 40 plants were completely immersed for $10 \mathrm{~min}$, after which plants were taken out of the bucket, drained of excess fluid, and planted within $30 \mathrm{~min}$. Each fungicide suspension was changed after treatment of every two batches of plants.

Fruiting field experiment design and fruit harvest. Plug plants and fresh-dug bare-root plants from the nursery experiments were planted on 16 October 2007 and 10 October 2008 for the 2007-08 (Yr1) and 2008-09 (Yr2) strawberry seasons, respectively, at the NCSU Horticultural Crops Research Station, Clinton, over $600 \mathrm{~m}$ away from the nursery site. Treatments were arranged in an RCBD employing eight standard fumigated, side-by-side raised plastic mulched beds with a buried drip-irrigation line. Each bed was $68.5 \mathrm{~cm}$ wide and $15 \mathrm{~cm}$ high, with a 1.5 -m center-to-center bed spacing. Each treatment unit or plot comprised two beds side by side and $3.8 \mathrm{~m}$ long. These plots were planted to bare-root or plug plants, with two rows of plants on each bed spaced $30 \mathrm{~cm}$ apart within rows and $45.7 \mathrm{~cm}$ apart between rows. Therefore, each treatment comprised 192 plants (12 plants per row, two rows per bed, two beds per plot, and four replications per treatment). Of the two beds in each treatment plot, plants from one bed were used for fruit harvest and plants from the other for plant biomass measurements by destructive sampling. Plots were staggered across the experimental site with $1.5 \mathrm{~m}$ of a nonplanted area between plots within the beds and nonplanted areas in adjacent beds to minimize interplot interference. Immediately after transplanting, plants were overhead irrigated with sprinklers for 7 to 10 days from 10:00 A.M. to 4:00 P.M. to prevent desiccation and aid in plant establishment, according to commercial practices. Commercially recommended preplant fertilization and other cultural practices were followed. All other irrigation and fertilization was done through the preset drip tape. No fungicides were applied during the growing season. Fruit were harvested and graded to marketable, diseased, and cull categories weekly from 5 April through 22 May 2008 and 21 April to 2 June 2009; delayed harvest in 2009 was due to delayed plant growth and fruit set due to weather. Marketable total yield in a treatment was analyzed based on the cumulative yield from the weekly harvests and calculated to represent average yield per hectare.

Plant mortality and disease progress. Plant mortality in the fruiting plots was recorded starting within a week after transplanting and every 7 to 15 days afterward until the end and middle of the harvest in Yr1 and Yr2, respectively. Disease incidence was scored on the beds designated for harvest. Wilted or dead plants were uprooted and crowns were cut longitudinally to check for diagnostic ACR symptoms. Reisolations of $C$. gloeosporioides from the crown of representative symptomatic plants were done either by incubating dissected crowns in a humid chamber or placing small surface-sterilized pieces on acidified potato dextrose agar to confirm the causal agent of plant wilting. Area under the disease progress curve (AUDPC) values were determined from plant mortality data taken throughout the growing season and estimated following the equation suggested by Shaner and Finney (1977) as:

$$
\mathrm{AUDPC}=\sum_{i=1}^{n_{i}-1}\left[\left(y_{i+1}+y_{i}\right) / 2\right]\left[t_{i+1}-t_{i}\right],
$$

where $y_{i}=$ the proportion of the strawberry plants wilted at $i$ th observation, $t_{i}=$ the time in days after observation of the disease at $i$ th day, and $n=$ the total number of observations.

Determination of plant vigor and dry biomass. Six plants were dug from the beds designated for plant destruction for each treatment in each sampling time following a preplanned sampling protocol that selected the second plant of the row on the same side of each bed, after which two plants were skipped to collect for the second sampling. Sampling was done once in the early spring at $10 \%$ bloom and then again at the end of the season, after the last fruit harvest. Each plant was dug with rhizosphere soil followed by careful shaking to remove loose soil particles. Plants were then washed thoroughly under high-pressure running water. Crowns and roots were separated from the foliage. Numbers of crowns were counted and root length from each plant was measured. Crown, root, and foliage from each replicate and treatment were put in separate paper bags and dried in an oven set at $70^{\circ} \mathrm{C}$ for 5 days, followed by recording of the dry biomass. Total foliage dry biomass data from $10 \%$ bloom and postharvest were combined and averaged because there was no significant sampling-treatment interaction between these two sampling dates.

Data analysis. The linear mixed-model (MIXED) procedure of SAS software (version 9.2; SAS Institute Inc., Cary, NC) was used to perform the analysis of variance for repeated data from plant mortality in different treatments. The experiment year (Yr1 and Yr2), treatment, and treatment-year were considered fixed effects whereas blocks and time of counts were random effects using an autoregressive covariance structure. Year effect for plant mortality was significant $(P=0.007)$ in the analysis of variance; thus, analyses were performed again and presented separately for each year. Linear regression analyses were performed separately for $\mathrm{Yr} 1$ and $\mathrm{Yr} 2 \mathrm{using}$ REG procedure in SAS to determine whether nursery inoculum levels, QI incidence, or QI severity could be used to predict AUDPC values or fruit yield loss of strawberry due to ACR. QI data were previously published (Rahman et al. 2015). Briefly, QI incidence levels ranged from 40 to $80 \%$, with severity values from 1 to $7 \%$ in inoculated plots, and the spread of inoculum from mother to daughter plants was highly influenced by distance and proportion of mother plants inoculated. Analysis of variance was performed to test for differences in angle (slope) and level based on grouped data (e.g., year-source of plants [I-sampled versus O-sampled plants]). Data were pooled by year for further regression analysis if differences in slope and level $(P=0.05)$ were not observed. Total marketable yield and plant biomass data were subjected to two-way analysis of variance where treatment, experimental repeats from Yr1 and Yr2, and treatment-year were considered as fixed effects and block was considered as a random effect. Means were separated by Fisher's protected least significant difference test at $\alpha=0.05$ with SAS software. Data were presented separately due to significant treatmentyear interactions.

\section{Results}

Plant mortality and ACR disease progress in the fruiting field in Yr1. Inoculation density in the nursery dramatically affected ACR incidence in fruiting fields. For example, a few plants started showing wilt symptoms as early as 7 days after planting in the fruiting field (Fig. 2A). These plants did not recover despite being under an overhead watering regime for an extended period of time (up to 10 days at 6 $\mathrm{h} /$ day). Further investigation of crown discoloration and isolation of the causal organism revealed that the crowns were infected with $C$. gloeosporioides. Crown infection within apparent healthy plants, together with planting shock, may have expedited plant mortality.

Asymptomatic tips were used to grow out plug plants and plug-plant mortality was modest in the greenhouse just prior to planting, with $29 \%$ mortality (Rahman et al. 2015). Any plug plant with wilt or black spots on leaves, diagnostic of $C$. gloeosporioides infections, was discarded. 
Nevertheless, plug plants in the fruiting field showed the highest mortality in the first and second weeks after planting (Fig. 2A, large arrow) followed by $25 \%$-I and 10\%-I (Fig. 2A). Within a month of planting, plant mortality in 25\%-I crossed the level of plugs and progressed steadily over the duration of the whole growing season, reaching $32 \%$ by the end of the harvest. After the first 2 weeks, plug plants did not show additional mortality until bloom and first harvest, then spiked during the harvest weeks and reached $19 \%$ by the end of the season, which was slightly higher than the $10 \%$-I treatment. Although $10 \%$-I had significantly lower plant mortality compared with $25 \%$-I, as determined by analysis of AUDPC values (Fig. 2B), both treatments showed similar trends of progressive plant mortality throughout the growing season in the fruiting field. Bare-root plants from noninoculated nursery plots had $0 \%$ plant mortality despite minor QI incidence and severity on leaves (Rahman et al. 2015) as revealed by the paraquat assay (Cerkauskas and Sinclair 1980). All treatments had significantly $(P \leq 0.05)$ higher AUDPC values compared with noninoculated treatments, except $10 \%$-O (Fig. 2B). However, plant mortality in the treatments other than $25 \%$-I, 25\%-Plug, or $10 \%$-I remained very low throughout the growing season ( 3 to $9 \%$ ), with mortality spiking near the end of the season. Plants immersed in fungicides (either Switch or Topsin-M) had significantly lower AUDPC values compared with nondipped $10 \%$-I plants but fungicide treatments did not reduce disease to the level of the noninoculated control (Fig. 2B).

Plant mortality and ACR disease progress in the fruiting field in Yr2. Overall plant mortality was lower in Yr2 compared with Yr1. Despite lower disease pressure, plant mortality showed a similar trend, with $25 \%$-I having highest plant mortality followed by $10 \%$-I (Fig. 3A and B). Plug plant mortality (25\%-Plug) remained very low throughout the growing season and reached only $5 \%$ at the final sampling date (Fig. 3A). Also, plant mortality immediately after transplant was very low in all treatments in Yr2. Plants from 5\%-O had the lowest (2.5\%) mortality incidence, similar to the noninoculated plants $(3.8 \%)$ based on AUDPC values (Fig. 3B). Percent plant mortality for 5\%-O, $25 \%$-Plug, $5 \%$-I, $10 \%$-O, and $25 \%$-O remained low (2.0 to $7.5 \%$ ) through the entire season. However, AUDPC values for 5\%-I, 10\%$\mathrm{O}$, and $25 \%$-O were significantly higher than the noninoculated control and 5\%-O (Fig. 3B). Fungicide immersion treatments significantly reduced AUDPC values compared with the nondipped 10\%-I treatment, with Switch being more effective than Topsin-M (Fig. 3A and B), but

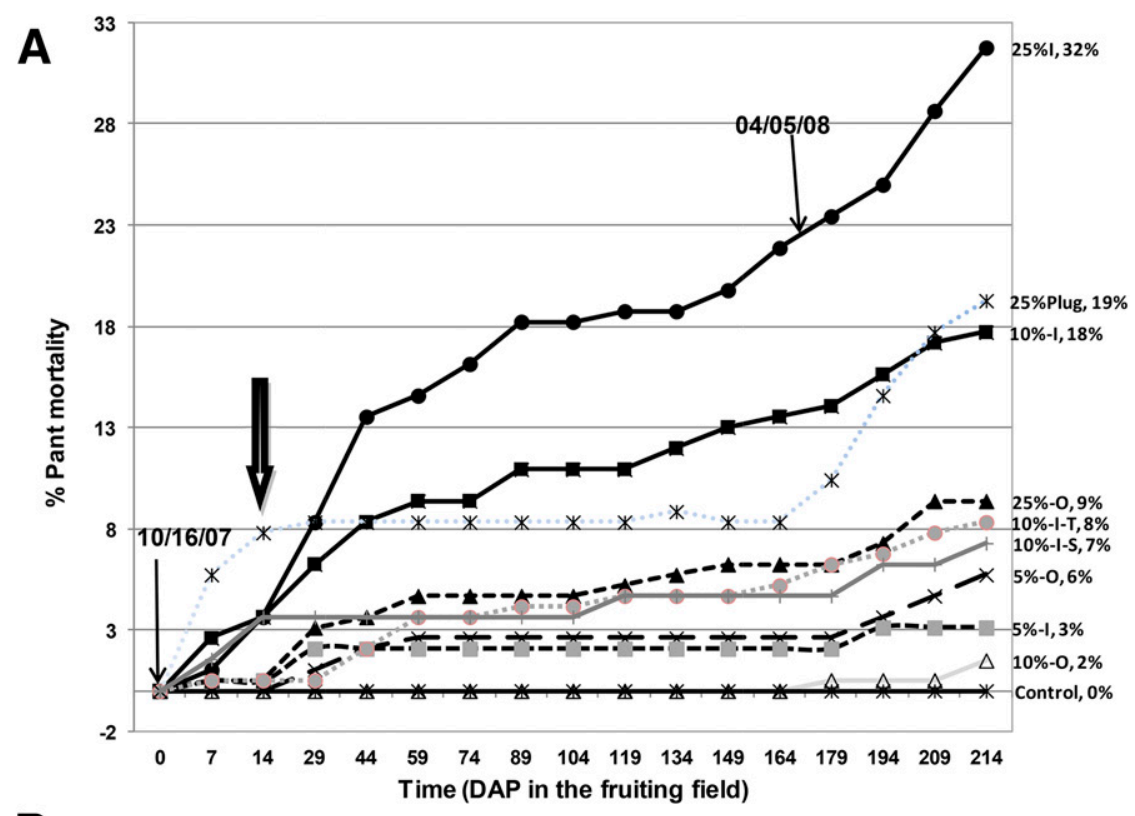

B

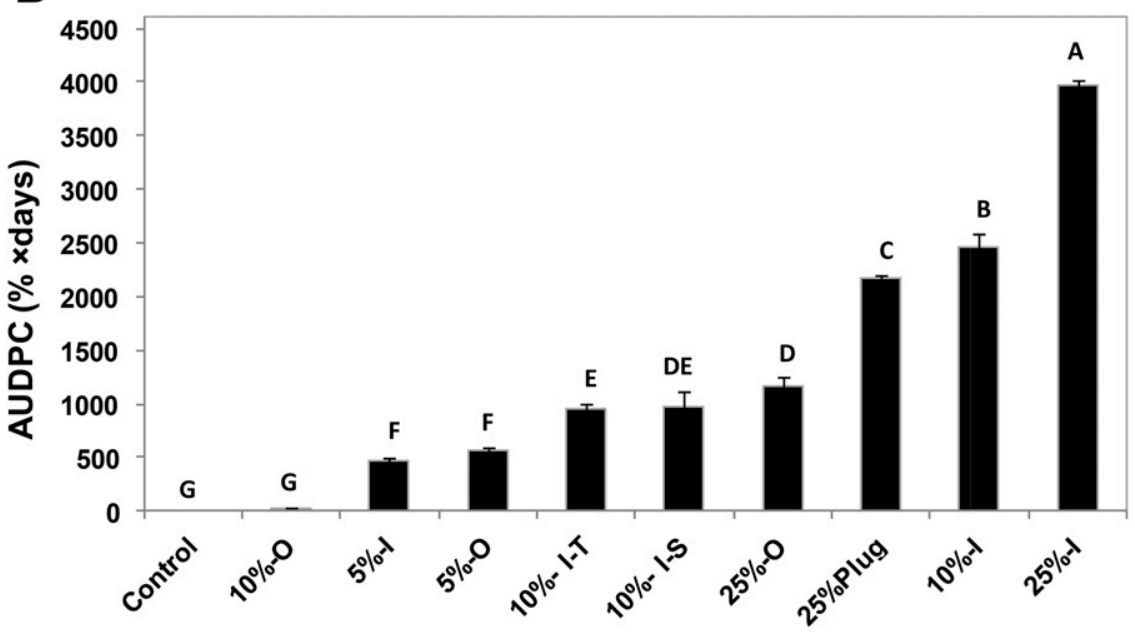

Fig. 2. A, Plant mortality and disease progress in the fruiting field during the 2007-08 ( $\mathrm{Yr} 1$ ) growing season. Labels to the right indicate the treatment and percent terminal plant mortality, which was averaged from the number of total dead plants in relation to total number of plants $(n=96)$ in a replicate plot $(n=4)$ in a treatment. Plant mortality was counted every 7 to 15 days after planting (DAP). The large arrow highlights early plant death described in the text and the small arrow represents first harvest. B, Area under the disease progress curve (AUDPC) for the plant mortality data in different treatments in the fruiting field in 2007-08. Bars with the same letter above them are not significantly different from one another according to Fisher's protected least significant difference test $(P=0.05)$. 
AUDPC values remained significantly greater than the noninoculated treatment (control).

Effect of QI plants on marketable yield and dry biomass Yr1. Bare-root plants from the noninoculated nursery treatment had the highest marketable yield in Yr1 followed by plug plants (Table 1), even though there was relatively high plant mortality in the plug plant treatment in the fruiting field (Fig. 2A). The lowest marketable yield was obtained from the $25 \%$-I treatment followed by $10 \%$-I and $25 \%$-O. These were significantly lower than the noninoculated treatment but there were no significant differences among themselves or several other treatments $(P=0.05$; Table 1$)$. Fungicide treatments of bare-root plants from $10 \%$-I increased yield such that the yield was statistically similar to the noninoculated treatment, although not significantly greater than the $10 \%$-I treatment not treated with fungicide. There were no significant differences in number of secondary crowns, root weight, or root length among the treatments (data not shown) and sampling date-treatment effects were not significant. Therefore, the plant dry biomass presented is the sum of all aboveground parts (except the crowns) and the mean of the two sampling dates. Plug plants tended toward the highest biomass compared with several inoculated treatments but few differences were observed in dry biomass among the inoculated and noninoculated treatments when apparently healthy plants were sampled in the spring, beginning at early bloom (Table 1 ).

Effect of QI plants on marketable yield and dry biomass Yr2. Marketable yield in Yr2 was comparable with that in Yr1 (Table 1). The highest marketable yield was obtained from plug plants followed
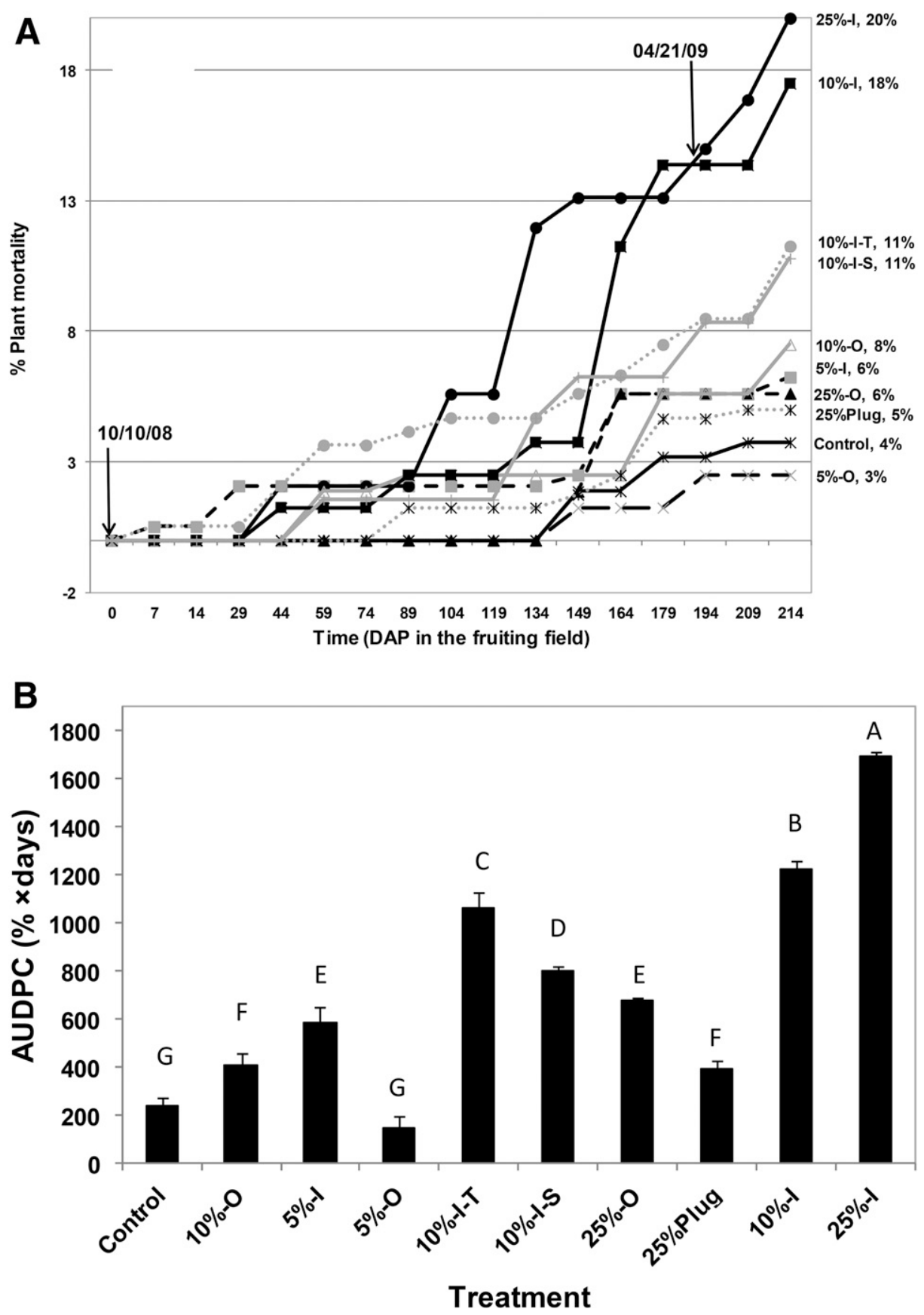

Fig. 3. A, Plant mortality and disease progress in the fruiting field during 2008-09 (Yr2) growing season. Labels to the right indicate the treatment and percent terminal plant mortality, which was averaged from the number of total dead plants in relation to total number of plants $(n=96)$ in a replicate plot $(n=4)$ in a treatment. Plant mortality was counted every 7 to 15 days after planting (DAP). The small arrow represents first harvest. B, Area under the disease progress curve (AUDPC) for the plant mortality data in different treatments in the fruiting field in 2008-09. Bars with the same letter above them are not significantly different from one another according to Fisher's protected least significant difference test $(P=0.05)$. 
by the noninoculated and the $5 \%$-O treatments. In contrast, the lowest marketable yield was obtained from the $25 \%$ (O and I) and $10 \%$-I treatments. Surprisingly, the $25 \%-\mathrm{O}$ generated a yield similar to that of the $25 \%$-I treatment despite low plant mortality in the $25 \%$-O treatment, suggesting that $C$. gloeosporioides infection has the potential to affect fruit yield with or without killing plants. This observation was consistent in both years of the study. Plug plant dry biomass was greater than the $25 \%$ treatments and similar to Yr1; there were no differences among the other treatments (Table 1). Similar to Yr1, Switch and Topsin-M treatments did not increase marketable yield compared with the $10 \%$-I treatment based on this analysis.

Regression analysis of impact of inoculum load on AUDPC and yield values. The percentage of mother plants inoculated in the nursery and subsequent QI incidence and severity values documented on the mother plants and surrounding runner plants (Rahman et al. 2015) had a dramatic and clear effect on yield and plant mortality in the fruiting fields (Tables 2 and 3; Fig. 4A and B). Regression curves did not differ significantly for angle or level related to plant source from the I or O sample region with regard to effect on yield; however, significant effects for I and O samples were observed for AUDPC values. Therefore, effects of I and O treatments on yield values were pooled (Table 2) and AUDPC values were not (Table 3). Likewise, analysis of variance for slope and angle showed no year effect in the relationship

Table 1. Total fruit yield and dry biomass production as affected by different treatments in two consecutive years of field trials using transplants that originated from nursery plots where 0 to $25 \%$ of the mother plants were inoculated with Colletotrichum gloeosporioides conidia

\begin{tabular}{llllll}
\hline & \multicolumn{2}{c}{ Yield $(\mathbf{k g} / \mathbf{h a})^{\mathbf{w}, \mathbf{z}}$} & & \multicolumn{2}{c}{$\begin{array}{c}\text { Dry biomass } \\
\text { (g/plant) }\end{array}$} \\
\cline { 2 - 3 } \cline { 5 - 6 } Treatmenty & $\mathbf{2 0 0 7 - 0 8}$ & $\mathbf{2 0 0 8}-\mathbf{0 9}$ & & $\mathbf{2 0 0 7 - 0 8}$ & $\mathbf{2 0 0 8 - 0 9}$ \\
\hline Noninoculated & $28,696 \mathrm{a}$ & $25,338 \mathrm{~b}$ & & $56.3 \mathrm{ab}$ & $36.0 \mathrm{ab}$ \\
5\% outer & $25,652 \mathrm{abc}$ & $24,570 \mathrm{bcd}$ & & $55.6 \mathrm{ab}$ & $35.9 \mathrm{ab}$ \\
5\% inner & $22,464 \mathrm{abc}$ & $22,672 \mathrm{de}$ & & $44.9 \mathrm{~b}$ & $31.8 \mathrm{ab}$ \\
10\% outer & $24,150 \mathrm{abc}$ & $23,539 \mathrm{cde}$ & & $46.2 \mathrm{~b}$ & $29.3 \mathrm{ab}$ \\
10\% inner & $20,664 \mathrm{bc}$ & $19,331 \mathrm{fgh}$ & & $41.0 \mathrm{~b}$ & $34.6 \mathrm{ab}$ \\
10\% I-Topsin-M & $22,880 \mathrm{abc}$ & $21,082 \mathrm{f}$ & & $40.3 \mathrm{~b}$ & $31.0 \mathrm{ab}$ \\
10\% I-Switch & $23,513 \mathrm{abc}$ & $21,776 \mathrm{ef}$ & & $54.2 \mathrm{ab}$ & $41.8 \mathrm{ab}$ \\
25\% outer & $20,675 \mathrm{bc}$ & $18,295 \mathrm{gh}$ & & $38.1 \mathrm{~b}$ & $26.9 \mathrm{~b}$ \\
25\% inner & $19,945 \mathrm{c}$ & $17,698 \mathrm{~h}$ & & $45.5 \mathrm{ab}$ & $26.3 \mathrm{~b}$ \\
25\% plug & $26,736 \mathrm{ab}$ & $27,833 \mathrm{a}$ & & $66.2 \mathrm{a}$ & $46.9 \mathrm{a}$ \\
\hline
\end{tabular}

${ }^{\mathrm{w}}$ Average of four replications and cumulative for 8 weekly harvests.

${ }^{x}$ Only live plants at the time of sampling were collected. Any wilted plant in the sampling unit was avoided. Data are means of dry plant biomass excluding root and crown from two samplings, each with four replications.

y Noninoculated $=0 \%$ mother plants inoculated; runner plants were collected for the fruiting field study outside (outer: 0.5 to $1.0 \mathrm{~m}$ ) or inside (inner) a $0.5-\mathrm{m}$ radius around an inoculated mother plant in the nursery where a total of $0,5,10$, or $25 \%$ of the mother plants were inoculated in the nursery plots.

${ }^{z}$ Column means followed by the same letter are not significantly different according to Fisher's protected LSD text $(P \leq 0.05)$.

Table 2. Effect of quiescent infection (QI) severity (as detected on mother and runner plants in the nursery) or terminal plant death in the fruiting field on yield ${ }^{y}$

\begin{tabular}{|c|c|c|c|c|c|c|}
\hline \multirow[b]{2}{*}{$\begin{array}{l}\text { Independent } \\
\text { variable }^{\mathrm{z}}\end{array}$} & \multicolumn{3}{|c|}{ Yr1 } & \multicolumn{3}{|c|}{ Yr2 } \\
\hline & $R^{2}$ & $\mathbf{b}(\mathbf{x})$ & $\begin{array}{c}P \\
\text { value }\end{array}$ & $R^{2}$ & $\mathbf{b}(\mathbf{x})$ & $\begin{array}{c}P \\
\text { value }\end{array}$ \\
\hline QI severity (mother) & 0.781 & $-1,123.6$ & 0.004 & 0.781 & $-1,123.6$ & 0.037 \\
\hline QI severity (runner) & 0.669 & $-2,099.6$ & 0.013 & 0.669 & $-2,099.6$ & 0.002 \\
\hline Plant death $(\mathrm{kg} / \mathrm{ha})$ & 0.559 & -239.3 & 0.033 & 0.559 & -239.3 & 0.028 \\
\hline
\end{tabular}

y Yr1 and Yr2 = 2007-08 and 2008-09 seasons, respectively. Effect of inoculum level and QI incidence were not affected by year (combined data are shown in Figure 4).

${ }^{\mathrm{z}}$ Mother or daughter plants were assessed for colonization of Colletotrichum gloeosporioides in leaf tissue using a paraquat assay and colonization was assessed as a function of incidence (percentage of leaves sampled with colonization) or severity (average leaf area of leaves with colonization). between inoculum level and yield; therefore, these data were combined into a single regression analysis. The combined regression documented that the inoculum levels, from 0 to $25 \%$, consistently reduced yield from a total of $25.9 \mathrm{t} / \mathrm{ha}$ down to $291.6 \mathrm{~kg} / \mathrm{ha}$ for every percent increase in inoculum level (Fig. 4A), with an $R^{2}$ value of $0.696(P=0.001)$. QI in the mother plants and runner plants, as measured in the nursery and prior to field setting in the fruiting field, also directly affected yield. Again, there were no differences in the slope or level of the regression lines for QI incidence data, enabling the data to be pooled across I, O, and year effect into single regression equations for the mother plant and runner plant data. Yield decreased $131.0 \mathrm{~kg} / \mathrm{ha}$ for every percent increase in QI incidence in the mother plants $\left(R^{2}=0.744, P=0.001\right.$; Fig. 4B). Yield decreased $118.7 \mathrm{~kg} / \mathrm{ha}$ for every percent increase in runner plant QI incidence $\left(R^{2}=0.674, P=0.001\right.$; data not shown). QI severity values affected yield differentially each year, with significant difference in levels $(P=0.02$ for mother plant effects and 0.007 for runner plant effects) but no differences in slope (not significant and $P=$ 0.07 for mother and runner plant effects, respectively). Regression values are presented in Table 2. Not surprisingly, terminal plant death incidence also had a direct effect on yield but the relationships were not as strong, with lower $R^{2}$ values; however, the $P$ values were significant at 0.033 (Yr1) and 0.028 (Yr2) (Table 2), resulting in a decrease of 239.3 to $366.1 \mathrm{~kg} / \mathrm{ha}$ for each percent increase in terminal plant death.

Similar relationships were observed with parameters that assessed nursery disease levels as they affected AUDPC values in the fruiting fields but the effect of I and O sources of plants tended to differentially affect regression curve parameters; therefore, the data could not be combined by plant source or year (Table 3 ). Data associated with the I plant sources tended to have a significant impact on AUDPC values (Table 3, bold) for both years. There was a poor relationship between parameters assessed on O plant sources and AUDPC values, possibly due to low disease levels (flatter slopes) associated with these treatments.

\section{Discussion}

The strawberry production system is complex, with a high risk of plant-associated pathogens, including $C$. acutatum (anthracnose fruit rot [AFR]); Xanthomonas fragariae (angular leaf spot), Phytophthora cactorum (Phytophthora crown rot and leather rot), viruses, and $C$. gloeosporioides, among others. This study documented that

Table 3. Effect of quiescent infection (QI) incidence or severity on area under the disease progress curve values (based on plant death incidence over time in the fruiting field) as affected by inoculum level and detected on mother and runner plants in the nursery ${ }^{\mathrm{x}}$

\begin{tabular}{lrrrrrrrr}
\hline & \multicolumn{3}{c}{ Inner $^{\mathbf{y}}$} & & \multicolumn{3}{c}{ Outer $^{\mathbf{y}}$} \\
\cline { 3 - 4 } \cline { 8 - 9 } Independent variable $^{\mathbf{z}}$ & $\boldsymbol{R}^{2}$ & \multicolumn{1}{c}{$\mathbf{b}(\mathbf{x})$} & $\boldsymbol{P}$ value & & $\boldsymbol{R}^{2}$ & $\mathbf{b}(\mathbf{x})$ & $\boldsymbol{P}$ value \\
\hline Yr1 & & & & & & & \\
Inoculum level & $\mathbf{0 . 9 2 2}$ & $\mathbf{1 6 3 . 2}$ & $\mathbf{0 . 0 4 0}$ & & $\mathbf{0 . 9 2 2}$ & $\mathbf{1 6 3 . 2}$ & 0.176 \\
QI incidence (mother) & $\mathbf{0 . 9 1 1}$ & $\mathbf{6 1 . 6}$ & $\mathbf{0 . 0 4 6}$ & & $\mathbf{0 . 9 1 1}$ & $\mathbf{6 1 . 6}$ & 0.311 \\
QI incidence (runner) & 0.769 & 61.6 & 0.120 & & 0.769 & 61.6 & 0.510 \\
QI severity (mother) & 0.524 & 441.9 & 0.276 & & 0.524 & 441.9 & 0.447 \\
QI severity (runner) & $\mathbf{0 . 9 9 6}$ & $\mathbf{1 2 3 0 . 7}$ & $\mathbf{0 . 0 0 2}$ & & $\mathbf{0 . 9 9 6}$ & $\mathbf{1 2 3 0 . 7}$ & 0.342 \\
Yr2 & & & & & & \\
Inoculum level & $\mathbf{0 . 9 0 2}$ & $\mathbf{5 5 . 0}$ & $\mathbf{0 . 0 5 0}$ & $\mathbf{0 . 9 0 2}$ & $\mathbf{5 5 . 0}$ & 0.091 \\
QI incidence & 0.874 & 28.6 & 0.064 & & 0.874 & 28.6 & 0.338 \\
$\quad$ (mother) & & & & & & \\
QI incidence (runner) & $\mathbf{0 . 9 5 8}$ & $\mathbf{3 9 . 9}$ & $\mathbf{0 . 0 2 1}$ & & $\mathbf{0 . 9 5 8}$ & $\mathbf{3 9 . 9}$ & 0.111 \\
QI severity (mother) & 0.757 & 212.4 & 0.130 & & 0.757 & 212.4 & 0.460 \\
QI severity (runner) & $\mathbf{0 . 9 0 2}$ & $\mathbf{8 4 6 . 5}$ & $\mathbf{0 . 0 5 0}$ & & $\mathbf{0 . 9 0 2}$ & $\mathbf{8 4 6 . 5}$ & $\mathbf{0 . 0 2 6}$ \\
\hline
\end{tabular}

x Parameters in bold highlight relationships that were described by linear regression models at $P<0.05$.

${ }^{y}$ Runner plants were collected for the fruiting field study outside ( 0.5 to $1.0 \mathrm{~m}$; outer) or inside (inner) a $0.5-\mathrm{m}$ radius around an inoculated mother plant in the nursery where a total of $0,5,10$, or $25 \%$ (inoculum level) of the mother plants were inoculated in the nursery plots.

${ }^{\mathrm{z}}$ Yr1 and Yr2 = 2007-08 and 2008-09 seasons, respectively. Mother or daughter plants were assessed for colonization of Colletotrichum gloeosporioides in leaf tissue using a paraquat assay and colonization was assessed as a function of incidence (percentage of leaves sampled with colonization) or severity (average leaf area of leaves with colonization). 
C. gloeosporioides inoculum in the nursery can dramatically affect crown rot severity and yield in fruiting fields, though the risk of catastrophic losses is less than that associated with AFR, where up to $70 \%$ or more yield loss can occur (Rahman et al. 2013). Wilt incidence in fruiting fields increased with the percentage of infected mother plants in the nursery, with up to 20 to $32 \%$ plant death in the fruiting field by the end of the fruiting season. The highest incidence of plant loss occurred when runner plants were selected from within a $0.5-\mathrm{m}$ radius of inoculated mother plants with an initial inoculation frequency of $25 \%$ in the nursery. This level of mortality resulted in low yields of 19,945 and $17,698 \mathrm{~kg} / \mathrm{ha}$ or a 30.5 to $30.2 \%$ decrease in marketable fruit in Yr1 and Yr2, respectively. It is important to note that, despite the high level of disease in many plots, AFR was not an issue in either year, with up to $97 \%$ of the fruit marketable (data not shown). When nursery plants were inoculated with less frequency (5 to $10 \%$ ) or runner plants were collected from 0.5 to $1.0 \mathrm{~m}$ beyond the inoculated mother plant, mortality incidence decreased to 2 to $9 \%$, depending on the year. Therefore, assessing the inoculum load in the nursery could be helpful to the nursery grower and fruit grower as an indicator of risk and the need for mitigation measures. A challenge is that the majority of mother and runner plants in the nursery remained asymptomatic, consistent with observations in commercial field settings. Therefore, we adopted an assay to assess the incidence and severity of QI. QI incidence, expressed as the proportion of sampled leaves with QI, was easier to assess than severity values based on amount of sporulation on leaves and, therefore, is the preferred parameter to measure. Sampling mother or runner plants generated a similar assessment of risk, suggesting that either type of plant material is suitable for sampling in the nursery. Development of detailed sampling protocols (number of leaves and pattern of sampling) within large nursery fields remains a challenge that requires additional work and can be assisted using quantitative polymerase chain reaction or other advanced detection complemented with robust sampling methods (Rahman et al. 2009).

Another advantage of assessing QI incidence in the nursery (in this case, 25 to 28 days before harvesting runner plants) was that the values obtained were predictive of the level of risk a fruit grower might experience in terms of negative yield effects. Yield decreased $131.0 \mathrm{~kg} / \mathrm{ha}$ for every percent increase in QI incidence in the mother plants and $118.7 \mathrm{~kg} / \mathrm{ha}$ for every percent increase in runner plant QI incidence. These estimates represent a combined calculation for each plant type because the parameters (slope and incidence) were surprisingly similar for the 2 years, despite different weather patterns (see below). The regression models developed provide predictive capacity to researchers and commercial growers about disease risk in fruiting fields, if no mitigation measures are implemented and if sampling and diagnostic protocols for QI determination can be refined. For example, this study flagged infected mother plants but, in a large nursery, the occurrence of infected mother plants is likely to be random and locating hot spots would need to be enabled by optimized sampling protocols (Gattone et al. 2016).

The direct relationship of nursery infestation levels to fruit yield indicates that mitigation measures in the nursery and selection of plants with low QI incidence will have a direct benefit in fruit production fields. Previous work (Rahman et al. 2015) demonstrated that there is a steep dispersal gradient from point sources of $C$. gloeosporioides inoculum (e.g., the inoculated mother plants) and suggests that roguing plants in and around the infection foci would reduce the risk of transferring infected runners from the nursery to the fruiting field. Rogueing would reduce disease incidence but, due to the high value of strawberry fruit, growers could still incur economic losses. For example, the 5\%-I and $10 \%-\mathrm{O}$ treatments experienced 6 and $8 \%$ incidence of plant wilt, respectively, in Yr2 (Fig. 3), with a significant decrease in yield (Table 1) of 2,666 kg/ha (10.5\% decrease) and 1,799 kg/ha (7.1\% decrease), respectively, compared with the noninoculated treatment. Based on a recent comprehensive analysis of costs of production with a prepicked price of $\$ 4.41 / \mathrm{kg}$ (\$2.00/lb.) in North Carolina fruiting fields (Rysin et al. 2015), this would result in a loss of gross revenue of $\$ 11,757$ and $\$ 7,934 / \mathrm{ha}$, respectively. In cases where disease incidence was high due to the $25 \%$-I treatment, a $30.2 \%$ (Yr2) loss in yield, for example, would result in a loss of $\$ 33,687 /$ ha for the fruit grower. Therefore, any disease in the fruiting field that may occur due to use of runner plants from approximately 5\% infected nursery mother plants can be costly to the fruit grower. In situations where plant supplies are limited and available plants may have some level of infection, the fruit grower may need to make a decision to buy (or not grow strawberry) and the nursery grower a decision to sell, these regression models provide an assessment of risk for both. However, such prediction models and decisions concerning risk will need to be respected with caution because dispersal of the pathogen and symptom expression can be influenced by prevailing temperatures, relative humidity, wind-driven rain events (Ntahimpera et al. 1999), and strawberry cultivars (MacKenzie et al. 2006).

The parameters measured in the nursery had less consistent and significant impact on AUDPC values compared with impacts on yield (compare Tables 2 and 3). AUDPC values were not as good of a predictor of yield (data not shown) as, for example, mother plant inoculation frequency ( 0 to $25 \%$ ) or QI incidence levels in the nursery. It appears that plant death and yield effects are not entirely related and this is suggested by portions of the data. For example, although $25 \%$-O had significantly lower plant mortality and AUDPC values compared with the $10 \%$-I and $25 \%$-I treatments, similar low yield suggests that $C$. gloeosporioides infection reduced overall productivity by affecting reproductive growth or through some other mechanism not known at this time. Although AUDPC has been widely used for ranking genotypes for disease resistance and frequently used to predict crop yield loss in models with varying degrees of accuracy (Mangandi et al.
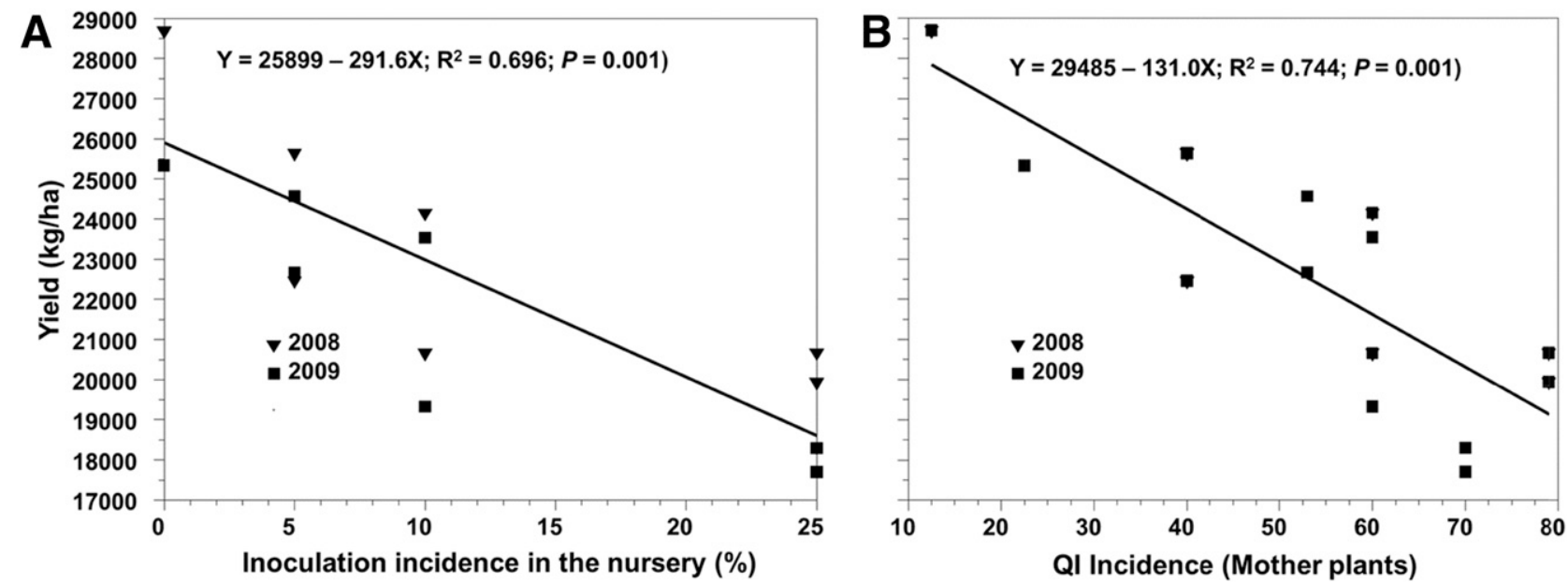

Fig. 4. Regression curves highlighting the relationship between inoculation levels in the nursery and $\mathbf{A}$, the incidence of quiescent infections (QI) detected in the nursery on mother plants and $\mathbf{B}$, impact on fruit yield the following spring. 
2015; Schneider et al. 1976; Shaner and Finney 1977; Shtienberg et al.1990), it has not been established for strawberry yield loss assessment, especially for ACR that initiates from QI. In contrast, the $25 \%$ I-plug treatments had AUDPC curves significantly greater than the noninoculated controls but had similar (Yr1; Table 1) or higher yields ( $\mathrm{Yr} 2)$, suggesting a compensation mechanism with this plant type, possibly due to higher biomass production compared with the worst treatments. Biomass reduction by diseases that affect photosynthetic capacity of plants is well documented (Comstock et al. 1992) but there is limited information on diseases that do not show any visible symptoms. In this study, whole plants with no symptoms were selected for the biomass assessment and this tendency of reduced vegetative growth could be one mechanism that affected yield without killing plants. Healthyappearing plants were not assayed for levels of Colletotrichum colonization at the end of the study. Although a set of runner plants was selected from within the $0.5-\mathrm{m}$ radius of the inoculated mother plants in each case, the overall level of QI and subsequent AUDPC values and yield in the fruiting field were affected by the overall level of inoculation in the nursery plots and as shown by the regression analysis of the data (Table 2; Fig. 4). This seems plausible with the $25 \%$ inoculation levels because mother plants were proximal to one another, with near-overlap in the 1-m sampled radius, and multiple mother plants could be an infection source for surrounding runner plants. However, runner plants were collected carefully to maintain designated distances for I and $\mathrm{O}$ treatments. These data suggest that inoculum levels did affect total inoculum load within the $0.5-\mathrm{m}$ area around each inoculated mother plant, even when these mother plants were more distant (e.g., in the $10 \%$ treatments). However, a low level of plant mortality in control treatments in Yr2 suggested that some inoculum moved from inoculated plots in the nursery to the control plots, possibly due to movement of labor crews during hand-weeding events or wind-driven rain dispersal of inoculum. These infected plants were subsequently moved to the fruiting field.

Another major outcome of this work is the documentation that infections in healthy-appearing plants are a clear and major issue for the strawberry industry. All plants in this study, including those from the plug production process, were selected to be asymptomatic at the time of transplanting. A number of plants died within 7 to 10 days, suggesting that crown rot symptoms were rather advanced after field setting. This early death frequently occurs in the plug production phase (Rahman et al. 2015) and commercial field settings and alerts growers and diagnosticians about planting-stock issues. Quiescently infected strawberry plants have long been considered the most important source of inoculum to the fruiting field, resulting in severe plant mortality and yield loss (Nam et al. 2004). Production of plug plants with QI tips also has been considered risky. This study showed that removing dead and symptomatic (black dots on leaves) plants from plug trays and planting only apparently healthy plugs in the fruiting field could still lead to high plant mortality (5 to $19 \%$ ).

Bare-root plants collected from noninoculated nursery plots with a low level of QI showed no or a low level of plant mortality in the fruiting field, confirming the importance of clean plants. Because our fruiting fields were also far away from possible alternative wild hosts, distribution of infected plants suggested that infected nursery plants were the only source of inoculum for fruiting fields in this study. Xiao et al. (2004) observed that strawberry plants with ACR symptoms could be aggregated at the edge of the fruiting field adjacent to noncultivated alternative wild hosts, indicating that distribution of infected plants could often be used to ascertain the source. However, the winters tend to be much cooler in North Carolina than Florida and epidemics in fruiting fields due to local sources of inoculum have not been documented. In addition, an empty buffer zone between treatment rows in the fruiting field in our study appeared to limit interplot interference and could keep plants in noninoculated plots relatively free from any infection. This observation further strengthens our previous results from the nursery study (Rahman et al. 2015) that dispersal within the nursery or fruiting field is minimal, likely due to low canopy height compared with alternative wild hosts of $C$. gloeosporioides. Cool winter temperatures would also suppress secondary spread within the fruiting field, although disease progress curves increased through the winter months, especially for the $25 \%$-I and $10 \%$-I treatments. It remains unclear whether this was a function of secondary spread from one plant to another or a function of disease expression within a plant infected earlier in the year. The strong link between fruit yield losses and initial sources of inoculum levels in the nursery suggests that secondary cycles are not a major factor in fruit production systems in climates similar to those in North Carolina. Also, many treatments resulted in very low or no disease progress through the winter, with an increase in the early spring, most pronounced for the $25 \%$-Plug treatment in Yr1 (Fig. 2A).

Temperatures are known to dramatically affect Colletotrichum disease in strawberry and may also explain the difference in disease levels between the 2 years. Higher mortality rates were observed in Yr1 than in $\mathrm{Yr} 2$, which could be explained by warmer temperatures during the nursery and fruiting field in the Yr1 cycles. Warmer temperatures could have favored more rapid symptom development or inoculum multiplication in the fruiting field. Smith and Spiers (1982) found that postinoculation incubation of strawberry plants at $35^{\circ} \mathrm{C}$ had higher disease severity ratings compared with plants incubated at 25 or $30^{\circ} \mathrm{C}$. Similar results were obtained by Rahman et al. (2015), where inoculated plants needed exposure to $32^{\circ} \mathrm{C}$ for ACR symptom expression. In addition, a recent study by Mangandi et al. (2015) evaluating strawberry accessions for resistance against ACR reported that high temperature strongly enhanced plant mortality. The importance of high temperature $\left(>25^{\circ} \mathrm{C}\right)$ and humidity for disease development in strawberry plants infected with $C$. fragariae was also shown by many other investigators both in the field (Chakraborty and Billard 1995) as well as in the greenhouse (Smith and Black 1987; Smith and Spiers 1982). Strawberry nurseries producing bare-root plants and tips in the mountain area in North Carolina usually develop low levels of ACR infection compared with coastal plain and piedmont production regions, where summer temperatures are usually higher, despite the presence of similar alternative wild hosts (F. J. Louws, personal observation). Weather data collected from a station located within $100 \mathrm{~m}$ of the nurseries and fruiting fields showed that the daily average temperatures during nursery and fruiting field cycles in $\mathrm{Yr} 1$ were 30.4 and $19.9^{\circ} \mathrm{C}$, respectively, compared with 27.2 and $19.0^{\circ} \mathrm{C}$ in $\mathrm{Yr} 2$. Total rainfall during the nursery and fruiting field in Yr1 was 19.1 and $65.9 \mathrm{~cm}$, respectively, compared with 59.1 and $57.0 \mathrm{~cm}$ during $\mathrm{Yr} 2$ production seasons. Wetness hours (usually affected by rainfall and relative humidity) and temperatures were found to be directly correlated with germination, secondary conidiation, and appressorial formation of $C$. acutatum on symptomless strawberry leaves (Leandro et al. 2003). Similar survival and inoculum multiplication mechanisms may be operative for $C$. gloeosporioides on strawberry foliage.

Seeking mitigation measures and translating them into commercial recommendations are important components of the research and extension mission. Fungicide dips consistently decreased AUDPC values and improved plant stand by 7 to $11 \%$. This did not increase yield compared with the $10 \%$-I treatment based on analysis of variance when analyzing all treatments. Fungicide dips represent a realistic first step in an IPM program to manage plants with known infections in cases when growers do not have access to plants from an alternative disease-free source. Supplemental spray application in the fruiting field has the potential to further reduce disease incidence subject to further studies and if secondary spread occurs, especially in the spring. The objective and design of this study did not allow application of additional in-field fungicides. The $10 \%$-I treatment had a modest level of infection, and perhaps fungicide effects would have been more dramatic if disease pressure was higher. Collection of runner plants from the $25 \%$-I treatment could have provided more discrimination between fungicide-treated and nontreated plants. However, collection of plants from this inoculation level for plug production resulted in a limited supply of runner plants. Active ingredients used in this study (thiophanate-methyl and cyprodinil) were effective in previous studies by Zhang and Timmer (2007) in reducing the incidence of postharvest anthracnose of tangerine caused by $C$. gloeosporioides when applied 2 days before harvest. Abril et al. (2008) found that cyprodinil was strongly inhibitory to the germination and growth of $C$. gloeosporioides in vitro. Our results are in agreement with these previous studies; however, complete recovery from QI with one dip treatment or even 
complementary multiple in-field applications is likely not possible, especially if infections occur in the crown during the nursery production cycle. MacKenzie et al. (2009) found that strobilurins (azoxystrobin and pyraclostrobin) were more effective when these products were applied 1 day after inoculation compared with 2 days before inoculation, and significant disease control required weekly applications of fungicide from planting to harvest for Florida climate conditions, which would increase production costs significantly. Sportak (prochloraz, research sample only; Bayer Crop Science, Raleigh, NC) in preliminary in vitro studies and 1 year of field data (data not shown) was by far the best effective fungicide against $C$. gloeosporioides. It is widely used for managing postharvest disease on mango (Coates et al. 1993; Swart et al. 2009) and avocado (McMillan and Narayanan 1991). This product is not available for commercial use in the United States but could be an important component of an IPM program where it is registered, especially when combined with emerging sources of host resistance (Mangandi et al. 2015).

ACR is a serious disease, particularly in southeastern strawberry production systems, and this study documents that plant infections in nursery fields can dramatically influence ACR incidence and yield and fruiting fields but that losses may not be catastrophic as compared with AFR. Sampling nursery plants, assessing QI incidence in the nursery, and sharing data with fruit produces should help in decision making about the need to rogue and implement management programs. In cases of a positive detection of infection, preplant fungicide treatments would reduce the incidence of plant mortality. Ultimately, the industry needs to develop a systems-wide approach to eliminate $C$. gloeosporioides from the propagation and fruiting field cycles; however, this will require more detailed work to understand the diversity and dynamics of the pathogen, detection and sampling protocols, and integration of multiple-tactics that may include use of fungicides, improved cultural practices, and development of durable host resistance in marketacceptable cultivars.

\section{Acknowledgments}

We thank Z. Pesic-Van Esbroeck for providing planting stocks for producing nursery plants, J. Driver and M. Carnes for their help with the field work, and the Horticultural Crops Research Station, Clinton, NC for outstanding support for our field experiments. This research was funded by a grant awarded to F. J. Louws by the United States Department of Agriculture Southern Region IPM program (contract number 2005-34103-16018) complemented with consistent support from the North Carolina Strawberry Association, North American Strawberry Growers Association, and Southern Region Small Fruit Consortium.

\section{Literature Cited}

Abril, M., Curry, K. J., Smith, B. J., and Wedge, D. E. 2008. Improved microassays used to test natural product-based and conventional fungicides on plant pathogenic fungi. Plant Dis. 92:106-112.

Brooks, A. N. 1931. Anthracnose of strawberry caused by Colletotrichum fragariae, n. sp. Phytopathology 21:739-744.

Cannon, P. F., Bridge, P. D., and Monte, E. 2000. Linking the past, present, and future of Colletotrichum systematics. Pages 1-20 in: Colletotrichum: Host Specificity, Pathology, and Host-Pathogen Interaction. D. Prusky, S. Freeman, and M. B. Dickman, eds. American Phytopathological Society, St. Paul, $\mathrm{MN}$.

Cerkauskas, R. F., and Sinclair, J. B. 1980. Use of paraquat to aid detection of fungi in soybean tissue. Phytopathology 70:1036-1038.

Chakraborty, S., and Billard, L. 1995. Quantitative relationship between Colletotrichum gloeosporioides infection of Stylosanthes scabra and weather under field conditions. Plant Pathol. 44:63-72.

Coates, L. M., Cooke, A. W., and Johnson, G. I. 1993. Postharvest disease control in mangoes using high humidity hot air and fungicide treatments. Ann. Appl. Biol. 123:441-448.

Comstock, J. C., Shine, J. M., Jr., and Raid, R. N. 1992. Effect of rust on sugarcane growth and biomass. Plant Dis. 76:175-177.

Delp, B. R., and Milholland, R. D. 1981. Susceptibility of strawberry cultivars and related species to Colletotrichum fragariae. Plant Dis. 65:421-423.

Durner, E. F., Poling, E. B., and Maas, J. L. 2002. Recent advances in strawberry plug transplant technology. HortTechnology 12:545-550.

Gattone, S. A., Mohamed, E., and Di Battista, T. 2016. Adaptive cluster sampling with clusters selected without replacement and stopping rule. Environ. Ecol. Stat. 23:453-468.

Gunnell, P. S., and Gubler, W. D. 1992. Taxonomy and morphology of Colletotrichum species pathogenic to strawberry. Mycol. 84:157-165.

Horn, N. L., and Carver, R. G. 1963. A new crown rot of strawberry plants caused by Colletotrichum fragariae. Phytopathology 53:768-770.
Howard, C. M., and Albregts, E. E. 1983. Black leaf spot phase of strawberry anthracnose caused by Colletotrichum gloeosporioides (=C. fragariae). Plant Dis. 67:1144-1146.

Howard, C. M., and Albregts, E. E. 1984. Anthracnose of strawberry fruit caused by Glomerella cingulata in Florida. Plant Dis. 68:824-825.

Leandro, L. F. S., Gleason, M. L., Nutter, F. W., Wegulo, S. N., and Dixon, P. A. 2003. Influence of temperature and wetness duration on conidia and appressoria of Colletotrichum acutatum on symptomless strawberry leaves. Phytopathology 93:513-520.

Legard, D. E., Whidden, A. J., and Chandler, C. K. 1998. Incidence and occurrence of strawberry diseases in Florida from 1991-1996. Adv. Strawberry Res. 16:35-47.

MacKenzie, S. J., Legard, D. E., Timmer, L. W., Chandler, C. K., and Peres, N. A. 2006. Resistance of strawberry cultivars to ACR caused by Colletotrichum gloeosporioides isolates from Florida is nonspecific. Plant Dis. 90:1091-1097.

MacKenzie, S. J., Mertely, J. C., and Peres, N. A. 2009. Curative and protectant activity of fungicides for control of ACR of strawberry caused by Colletotrichum gloeosporioides. Plant Dis. 93:815-820.

Mangandi, J., Peres, N. A., and Whitaker, V. M. 2015. Identifying resistance to crown rot caused by Colletotrichum gloeosporioides in strawberry. Plant Dis. 99:954-961.

McInnes, T. B., Black, L. L., and Gatti, J. M., Jr. 1992. Disease-free plants for management of strawberry anthracnose. Plant Dis. 76:260-264.

McMillan, R. T., Jr., and Narayanan, K. R. 1991. Effectiveness of chemical postharvest treatments for avocado anthracnose control. Proc. Ann. Fla. State Hortic. Soc. 103:232-233.

Mills, P. R., Sreenivasaprasad, S., and Brown, A. E. 1992. Detection and differentiation of Colletotrichum gloeosporioides isolates using PCR. FEMS Microbiol. Lett. 98:137-143.

Nam, M. H., Lee, I. H., Kwon, K. H., and Kim, H. G. 2004. Significance and detection of quiescent infection of Colletotrichum gloeosporioides on strawberry. Korean J. Hortic. Sci. Technol. 22:294-297.

Ntahimpera, N., Wilson, L., Ellis, M., and Madden, L. 1999. Comparison of rain effects on splash dispersal of three Colletotrichum species infecting strawberry. Phytopathology 89:555-563.

Prusky, D., and Lichter, A. 2008. Mechanisms modulating fungal attack in postharvest pathogen interactions and their control. Pages 281-289 in: Sustainable Disease Management in a European Context. D. B. Collinge, L. Munk, and B. M. Cooke, eds. Springer, New York.

Rahman, M., Ballington, J., and Louws, F. J. 2013. Role of foliar hemibiotrophic and fruit resistance in anthracnose-resistant strawberry genotypes for annual hill plasticulture systems. Ann. Appl. Biol. 163:102-113.

Rahman, M., Carnes, M. E., and Louws, F. J. 2009. Real-time PCR systems aid in quantitative detection of Colletotrichum spp. in spatial dispersal studies of strawberry anthracnose. (Abstr.) Phytopathology 99:S107.

Rahman, M., Ojiambo, P. S., and Louws, F. J. 2015. Initial inoculum and spatial dispersal of Colletotrichum gloeosporioides, the causal agent of strawberry anthracnose crown rot. Plant Dis. 99:80-86.

Rysin, O., McWhirt, A., Fernandez, G., Louws, F. J., and Schroeder-Moreno, M. 2015. Economic viability and environmental impact assessment of three different strawberry production systems in Southeastern United States. HortTechnology 25:585-594.

Schneider, R. W., Williams, R. J., and Sinclair, J. B. 1976. Cercospora leaf spot of cowpea: Models for estimating yield loss. Phytopathology 66:384-388.

Shaner, G., and Finney, R. E. 1977. The effect of nitrogen fertilization on the expression of slow-mildewing resistance in Knox wheat. Phytopathology 67:1051-1056.

Shtienberg, D., Bergeron, S. N., Nicholson, A. G., Fry, W. E., and Ewing, E. E. 1990. Development and evaluation of a general model for yield loss assessment in potatoes. Phytopathology 80:466-472.

Smith, B. J. 2008. Epidemiology and pathology of strawberry anthracnose: A North American perspective. HortScience 43:69-73.

Smith, B. J., and Black, L. L. 1987. Resistance of strawberry plants to Colletotrichum fragariae affected by environmental conditions. Plant Dis. 71:834-837.

Smith, B. J., and Spiers, J. M. 1982. Evaluating techniques for screening strawberry seedlings for resistance to Colletotrichum fragariae. Plant Dis. 66:559-561.

Sreenivasaprasad, S., Brown, A. E., and Mills, P. R. 1992. DNA sequence variation and interrelationships among Colletotrichum species causing strawberry anthracnose. Physiol. Mol. Plant Pathol. 41:265-281.

Sreenivasaprasad, S., Mills, P. R., Meehan, B. M., and Brown, A. E. 1996 Phylogeny and systematic of 18 Colletotrichum species based on ribosomal DNA spacer sequences. Genome 39:499-512.

Swart, S. H., Labuschagne, C., Swart, G., and Serfontein, J. J. 2009. Chemical control of post-harvest diseases of mango: The effect of fludioxonil and prochloraz on soft brown rot, stem-end rot and anthracnose. Acta Hortic. 820:503-510.

Ureña-Padilla, A. R., MacKenzie, S. J., Bowen, B. W., and Legard, D. E. 2002 Etiology and population genetics of Colletotrichum spp. causing crown and fruit rot of strawberry. Phytopathology 92:1245-1252.

Weir, B., Johnston, P. R., and Damm, U. 2012. The Colletotrichum gloeosporioides species complex. Stud. Mycol. 73:115-180.

Xiao, C. L., MacKenzie, S. J., and Legard, D. E. 2004. Genetic and pathogenic analyses of Colletotrichum gloeosporioides isolates from strawberry and noncultivated hosts. Phytopathology 94:446-453.

Zhang, J., and Timmer, L. W. 2007. Preharvest application of fungicides for postharvest disease control on early season tangerine hybrids in Florida. Crop Prot. 26:886-893. 